\title{
Therapy of autoinflammatory diseases: results from an international registry
}

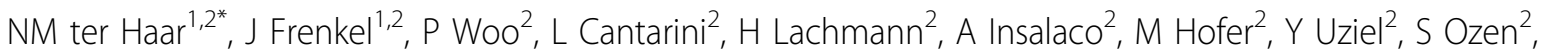 \\ S Nielsen², A Naselli², C Modesto², SM Al-Mayouf ${ }^{2}$, I Kone-Paut ${ }^{2}$, I Nikishina², N lagaru², L Obici², \\ E Papadopoulou-Alataki², D Rigante ${ }^{2}$, C Boros $^{2}$, A Martini' ${ }^{2}$, N Ruperto², M Gattorno ${ }^{2}$
}

From 18th Pediatric Rheumatology European Society (PReS) Congress

Bruges, Belgium. 14-18 September 2011

\section{Background}

The evidence for therapy in autoinflammatory diseases is limited. There are few randomized controlled trials or disease registries.

\section{Aim}

To evaluate the response to treatment of autoinflammatory diseases based on data of an international registry.

\section{Methods}

A web-based registry collecting baseline and clinical information of autoinflammatory diseases was located at the member area of the PRINTO website (www.printo. it). Participating hospitals included pediatric rheumatology centers of the PRINTO network and adult centers with a specific interest in autoinflammatory diseases. Data was collected on Blau's syndrome, Behçet's disease, CAPS, CRMO, DIRA, FMF, MKD, NLRP12-mediated periodic fever, PAPA, PFAPA TRAPS and undefined periodic fevers. In total, 704 patients were included in this retrospective study on therapy.

\section{Results}

NSAIDs and steroids were beneficial in most diseases. Anakinra induced a complete response in $70 \%$ of 40 treated CAPS patients, $82 \%$ of 28 TRAPS patients and in both DIRA patients. Furthermore, it was beneficial in $80 \%$ of 10 MKD patients. Etanercept was completely effective in all 6 Behçet patients, 34\% of 32 TRAPS patients and $13 \%$ of 8 MKD patients and partially effective in $53 \%$ of TRAPS and $38 \%$ of MKD patients. Colchicine was beneficial in approximately $95 \%$ of 131 FMF

\footnotetext{
* Correspondence: n.m.terhaar@students.uu.nl

${ }^{1}$ Department of Pediatrics University Medical Center Utrecht, Netherlands Full list of author information is available at the end of the article
}

and 18 Behçet patients, although the complete response rate was just $56 \%$ and $22 \%$, respectively. For PFAPA syndrome, corticosteroids aborted the attacks in $78 \%$ of 113 patients.

\section{Conclusion}

The results were compared to the literature. These combined findings could serve as a base for therapeutic guidelines and identify candidate drugs for future therapeutic trials.

\section{Author details \\ ${ }^{1}$ Department of Pediatrics University Medical Center Utrecht, Netherlands. ${ }^{2}$ For the PRINTO and Eurofever Project.}

Published: 14 September 2011

doi:10.1186/1546-0096-9-S1-P18

Cite this article as: ter Haar et al:: Therapy of autoinflammatory diseases: results from an international registry. Pediatric Rheumatology 20119 (Suppl 1):P18.

Submit your next manuscript to BioMed Central and take full advantage of:

- Convenient online submission

- Thorough peer review

- No space constraints or color figure charges

- Immediate publication on acceptance

- Inclusion in PubMed, CAS, Scopus and Google Scholar

- Research which is freely available for redistribution

Submit your manuscript at www.biomedcentral.com/submit
C Biomed Central

\section{Biomed Central}

(c) 2011 ter Haar et al; licensee BioMed Central Ltd. This is an open access article distributed under the terms of the Creative Commons Attribution License (http://creativecommons.org/licenses/by/2.0), which permits unrestricted use, distribution, and reproduction in any medium, provided the original work is properly cited. 